\title{
Osteoartropatía hipertrófica en paciente con carcinoma epidermoide de pulmón
}

\author{
Hypertrophic osteoarthropathy in a patient \\ with epidermoid lung cancer
}

Presentamos el caso de un varón de 72 años diagnosticado de carcinoma epidermoide estadio T2aNOMO, intervenido quirúrgicamente. Un año después, el paciente presentó recidiva tumoral loco-regional en forma de nueva masa pulmonar en lóbulo superior izquierdo (figura 1). En la exploración física se objetivó ensanchamiento no doloroso a la palpación de las falanges distales de todos los dedos de las extremidades superiores, así como de la falange distal de los primeros dedos de ambos pies (figuras 2 y 3). La gammagrafía ósea con tecnecio-99 mostró captación patológica en la región cortical de ambos fémures, compatible con osteoartropatía hipertrófica (figura 4).

La osteoartropatía hipertrófica (OAH) es un síndrome clínico en el que se desarrolla una periostitis crónica proliferativa de huesos largos, una deformación de los dedos de las manos y de los pies en palillo de tambor (dedos hipocráticos) y una sinovitis oligo o poliarticular ${ }^{1}$. Hay numerosos procesos asociados a la presencia de acropaquias y/0 osteoartropatía hipertrófica ${ }^{2,3}$ :

\section{Acropaquias idiopáticas, familiares.}

\section{Acropaquias adquiridas asociadas} a enfermedades:

- Cardíacas: congénitas, endocarditis bacteriana subaguda.

- Pulmonares: carcinoma de pulmón y pleura, bronquiectasias, absceso pulmonar, empiema, tuberculosis, fístulas arteriovenosas pulmonares, fibrosis pulmonar intersticial, neumoconiosis, fibrosis quística y proteinosis alveolar.

- Gastrointestinales: enteritis regional, enfermedades inflamatorias intestinales, cirrosis, disentería bacteriana, acalasia, úlcera péptica, amiloidosis hepática y carcinoma de esófago o colon.

- Endocrinas: tirotoxicosis.

- Miscelanea: abuso de laxantes, sífilis, polimiositis, extremidades hemipléjicas.
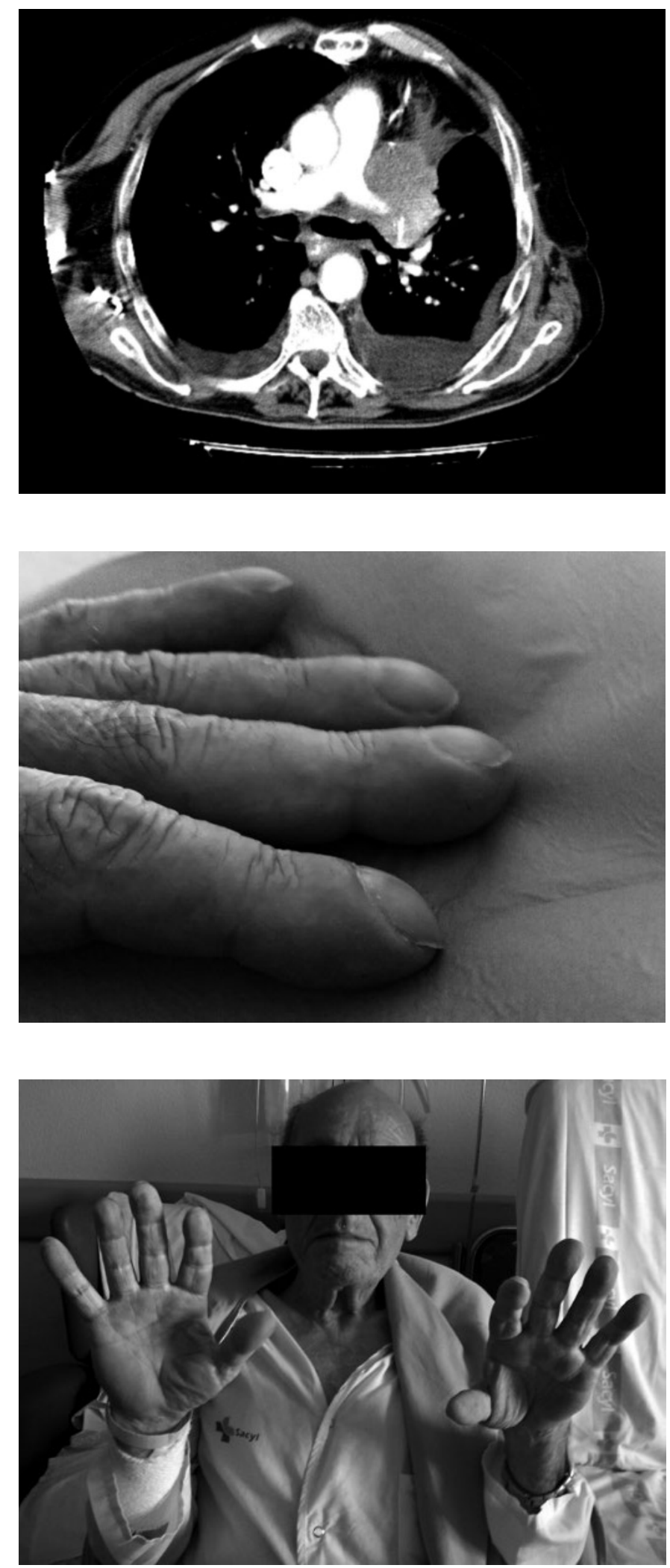
3. Osteoartropatía hipertrófica (síndrome de MariBamberger):

- Paquidermoperiostosis familiar

- Enfermedades cardíacas: infección del injerto de by-pass aórtico

- Enfermedades pulmonares: cáncer de pulmón primario, tumor pulmonar metastático y tumores pleurales.

- Miscelanea: carcinoma de tiroides, leiomioma de esófago, linfoma torácico, carcinoma nasofaríngeo y leucemia mieloide crónica.

Radiológicamente en la $\mathrm{OAH}$ la periostitis suele evidenciarse en huesos tubulares como una fina línea esclerótica, separada del córtex por una línea radiolucente. Los huesos afectados con mayor frecuencia son radio, cúbito, tibia y fémur; raramente falanges, clavículas, costillas, escápula y mandíbula. La gammagrafía con tecnecio 99 puede detectar precozmente la presencia de $\mathrm{OAH}$, antes que aparezcan manifestaciones clínicas y/o radiológicas. A diferencia de la enfermedad metastática la captación isotópica en la $\mathrm{OAH}$, se concentra en zona pericortical y periarticular ${ }^{3}$.

\section{Bibliografía}

1. Urruticoechea $A$, Horcada L, Delgado $C$ et al. Varón con neoplasia de pulmón metastatizada y síndrome paraneoplásico múltiple. Rev Esp Reumatol 2003; 30:23-6

2. Arias Muñana E, Calvo Plaza I, García Franco CE et al. Osteoartropatía hipertrófica pnéumica. Reemo 2001; 10: 199-200

3. Diez Jarilla JL. Problemas clínicos en aparato respiratorio: toma de decisiones. Grafinter SL Madrid 1996; 66-74

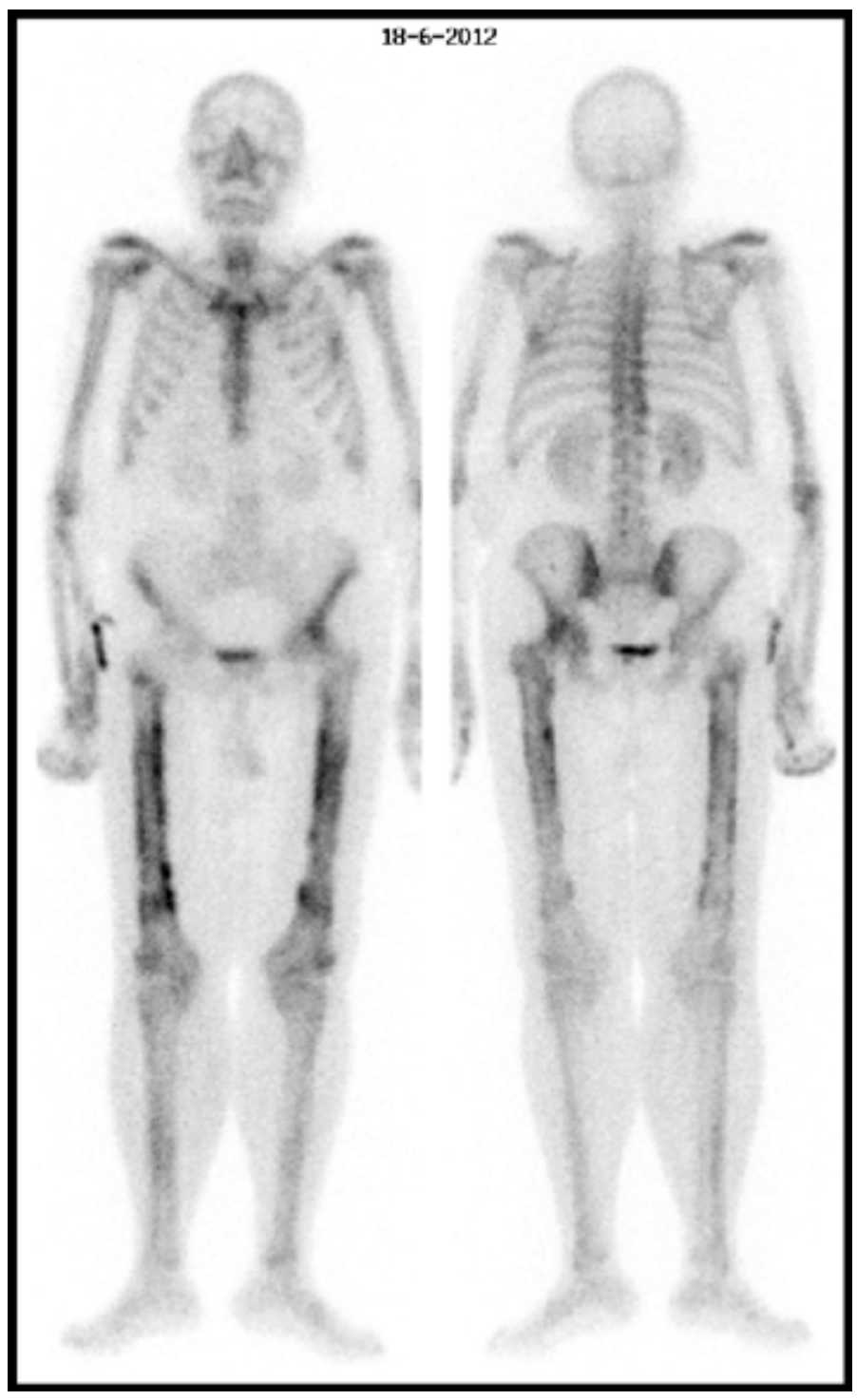

\section{Diagnóstico}

Osteoartropatía hipertrófica en paciente con carcinoma epidermoide de pulmón

\section{S Zhilina, M Fernandez}

Servicio de Medicina Interna. Hospital Clínico de Salamanca

Como citar este artículo: Zhilina S, Fernandez $M$

Osteoartropatía hipertrófica en paciente con carcinoma epidermoide de pulmón.

Galicia Clin 2013; 74 (1): 39-40

Recibido: 30/9/2012; Aceptado: 19/12/2012 